\title{
Comment
}

\section{Prática Docente, Educação e Sociedade}

Francisca Ilka Oliveira Bezerra da Costa ${ }^{I}$; Iarê Lucas Andrade ${ }^{2}$

Resumo: O presente artigo é uma revisão bibliográfica sobre educação, trabalho e sociedade. Uma análise baseada $\mathrm{m}$ alguns estudos sobre a temática, procurando conhecer aspectos históricos, desde os primórdios da humanidade, divisão das sociedades em classes trabalhistas, movimentos sociais da política educacional, valorização dos trabalhos da educação, o reconhecimento e, a valorização do homem como sujeito no processo trabalhista e educativo. Tenta-se analisar a escola e sua relevância para uma efetiva transformação social. Constatou-se que é através da educação que se pode observar mudanças na sociedade, mesmo levando-se em conta, que se vive num mundo de constantes mudanças econômicas, sociais políticas e culturais e que, a informação possibilita uma bagagem cultural importante e necessária ao exercício da cidadania.

Palavras-chave: Educação; Trabalho e Sociedade

\section{Teaching Practice, Education and Society}

\begin{abstract}
This article is a bibliographical review on education, work and society. An analysis based on some studies on the subject, seeking to know historical aspects, from the beginnings of humanity, dividing societies into labor classes, social movements of educational policy, valuing the work of education, recognition and appreciation of man as subject in the labor and educational process. It attempts to analyze the school and its relevance to an effective social transformation. It has been observed that it is through education that one can observe changes in society, even taking into account that one lives in a world of constant economic, social, political and cultural changes, and that information enables a cultural baggage important and necessary to the citizenship.
\end{abstract}

Keywords: Education; Work and Society

\section{Introdução}

No Brasil a desvalorização dos trabalhadores é muito grande principalmente do ramo da educação onde tem suas raízes na divisão social do trabalho de acordo com o contexto histórico da sociedade brasileira.

Este artigo tem como objetivo resgatar o reconhecimento e da importância e da contribuição dos trabalhadores da educação básica para o desenvolvimento do país como também da história da divisão do trabalho o seu desprestígio que sofreu na sua função por parte

\footnotetext{
${ }^{1}$ Mestrado em Ciências da Educação pela Anne Sullivan Uiversity. Autor correspondente: francsica_ilka@hotmail.com;

${ }^{2}$ Professor da Universidade Regional do Cariri - URCA. Contato: iareluc@gmail.com 
da sociedade e a luta constante para resgatar os valores e reconhecimento no processo educativo, processando ser valorizado pelos pais, funcionário e comunidades externas.

Pode-se dizer que desde o início da história do ser humano vive-se em constante luta de trabalho para garantir a sua sobrevivência principalmente no regime capitalista onde o poder fica concentrado, nas mãos da minoria da classe dominante.

Sabe-se que as transformações na sociedade se dá através da educação da cidadania, requer as questões socioculturais seja apresentada para aprendizagem e a reflexão dos cidadãos, abrindo um espaço mais democrático para as discussões, buscando um tratamento didático e transversal.

O ser humano é dotado de expectativas e a escola é o espaço onde elas se realizam. É nela que ser humano constrói sua cidadania, sua responsabilidade; acredita-se que nela também acontece a formação de indivíduos capazes de aprender e criar novos conhecimentos e se realizar através do seu trabalho como cidadãos conscientes para atuar na sociedade de forma mais justa e igualitária.

\section{A Educação no Brasil}

Espera-se que a educação no Brasil resolva sozinha, os problemas sociais do país. No entanto, é preciso primeiro melhorar a formação dos docentes, visto que o desenvolvimento dos processos implica no desenvolvimento dos alunos e da escola.

Ao propor uma reflexão sobre a educação brasileira, vale lembrar que só em meados do século XX o processo de expansão da escolarização básica no país começou, e que o seu crescimento, em termos de rede pública de ensino, se deu no fim dos anos de 1970 e início dos anos de 1980

Com isso posto, podemos nos voltar aos dados nacionais.

O Brasil ocupa o $53^{\circ}$ lugar em educação entre 65 países avaliados (PISA). Mesmo com o programa social que incentivam a matrícula de $98^{\circ}$ de crianças que estudam entre 6 e 12 anos, 731 mil crianças ainda estão fora da escola (IBGE). O analfabetismo funcional de pessoas entre 15 e 64 anos foi registrado entre $28 \%$ no ano de 2009 (IPOBE); 34 dos alunos que chega ao $5^{\circ}$ ano de escolarização ainda não conseguem ler (Todos pela educação) $20 \%$ dos jovens que 
concluem o ensino fundamental e que moram nas grandes cidades, não dominam o uso da leitura e da escrita (todos pela educação), professores recebem menos que o piso salarial (ABRUCIO, 1998).

Frente aos dados, muitos podem se tornar críticos e até se indagar com questões a respeito dos avanços conduzindo que "se a sociedade muda, a escola só poderia evoluir com ela"! Talvez o bom censo surgi se pensarmos dessa forma. Entretanto, podemos notar que a evolução da sociedade, de certo modo, faz com que a escola se adapte para uma vida moderna, mas de maneira defensiva, tardia, sem garantir a elevação do nível da educação. Logo agora, não mais pelo bom senso e sim pelo costume, a "culpa" tenderia a cair sobre o profissional docente. Dessa forma, os professores se tornam alvos ou ficam no fogo cruzado de muitas esperanças sociais e políticas em crise nos dias atuais. As críticas externas ao sistema educacional cobram dos professores cada vez mais trabalho, como se a educação sozinha, tivesse que resolver todos os problemas sociais.

Já sabemos que não basta, como se pensou nos anos de 1950 e 1960, dotar professores de livros e novos materiais pedagógicos. O fato é que a qualidade da educação está fortemente aliada à qualidade da formação dos professores. Outro fato é que o professor pensa sobre o ensino, determina que o professor faz quando ensina. O desenvolvimento dos professores é uma precondição para o desenvolvimento da escola e, em qual, a experiência demonstra que os docentes são mais executores das ideias dos outros. Nenhuma reforma, inovação ou transformação.

Como queria chamar - perdurassem o docente. É preciso abandonar a crença de que as atividades dos professores só se modificam na medida em que os docentes percebem resultados positivos na aprendizagem dos alunos. Para uma mudança efetiva de crença e de atitude, caberia considerar os professores como sujeitos. Sujeitos que em atividade profissional, são levados a se envolver em situações formais de aprendizagem.

Mudanças profundas só acontecerão quando a formação dos professores deixa de ser um processo de atualização, feita de cima para baixo e se converter em um verdadeiro processo de aprendizagem, como um ganho individual e coletivo, e não como uma agressão. Certamente, os professores não podem ser tomados como atores únicos nesse cenário. Podemos concordar que tal situação também é resultado de pouco engajamento e pressão por parte da população como um todo que contribuí a lentidão. Ainda sem citar o corporativismo das instancias 
responsáveis pela gestão - não só do sistema de ensino, mas também das unidades escolares e também os mitos de nossos contemporâneos que pensam, sem ousar dizer em voz alta, "que todos fossem instruídos, quem varreria as ruas?" ou que não vêem problema "em dispensar a todos das formações de alto nível”, quando os empregos disponíveis não os exigem.

Enquanto isso, nós continuamos longe de atingir a meta de alfabetizar todas as crianças até os 8 anos de idade e carregando o fardo de um baixo desempenho no IDEB, com índice de aprovação na média de 0 a 10, os estudantes brasileiros tiveram a pontuação de 4,6 em 2009. A meta do país é de chegar a 6 em 2022.

A valorização dos trabalhadores da educação básica, os movimentos sociais e a política educacional.

A desvalorização dos trabalhadores em educação, no seu todo ${ }^{3}$ é um processo histórico que se explica pela evolução de estrutura social do capitalismo na sociedade brasileira e pelas diferentes conjunturas vividas por esses trabalhadores. Esta desvalorização provocou, nas classes trabalhadoras, reações de defesa dos seus interesses e de reafirmação do seu valor profissional.

No final dos anos de 1970 e durante toda a década de 1980, com a chamada "redemocratização" do país, eclodem movimentos sociais vários com destaque para o dos educadores compromissados com a escola pública, gratuita, laica e de qualidade. ${ }^{4}$ Educadores realizam as Conferencias Brasileiras de Educação (CBEs), articulam-se no fórum nacional em defesa da escola pública, por ocasião da tramitação da atual LDB, organizam-se na Associação Nacional pela formação dos profissionais da Educação (Anfrop.) e intensificam suas lutas sindicais. ${ }^{5}$

Em todos esses espaços e movimentos, destaca-se luta pela valorização dos profissionais da educação, aí incluídos os professores de todos os níveis de ensino e os funcionários de escolas. Geraram-se muitos debates, propostas e intervenções concretas que objetivam resgatar

\footnotetext{
${ }^{3}$ A partir dos anos de 1980, também os professores do ensino superior tem perdas salariais significativas e tem seu prestigio social afetado pela massificação da categoria.

${ }^{4}$ Esta qualidade é a que passou a ser designada, nos anos de 1990, como qualidade social de educação ou educação socialmente referenciada, em oposição ao conceito neoliberal de qualidade total.

${ }^{5}$ Os sindicalistas, como "criaturas do capitalismo", são a principal resposta orgânica encontrada pelos trabalhadores em educação para lutarem contra a desvalorização salarial e profissional, através de reivindicações por pesos salariais nacionais dignos, carreira unificada e melhores condições de trabalho, proliferem greves e sindicatos das mais diversas categorias profissionais, aí se incluindo professores dos vários graus de ensino e funcionários de escolas, que passam a se organizar horizontal e verticalmente de diferentes formas. Foi um momento muito rico de debates políticos e de afirmação do chamado sindicalismo "combativo e classista" organizado de modo mais amplo na Central Única dos Trabalhadores (CUT). Os professores do ensino superior organizam-se, em 1981, na Andes (hoje Sindicato Nacional) e os funcionários das escolas superiores na Fasubra. Os professores e funcionários da educação básica se integram à CNTE e todos os trabalhadores da educação têm, em princípio, um espaço comum de organização vertical no DNTE/ CUT.
} 
o valor social dos intelectuais trabalhadores e a unidade de uma educação pública crítica e comprometida com a transformação social. Tem-se, a partir de então, uma intensa e consistente luta dos trabalhadores, na sua condição de classes subalternas, pela construção de uma política educacional compatível com os reais interesses dessas classes.

Essa luta prossegui nos dias atuais, cabendo destaque aos esforços empreendidos pela confederação nacional dos trabalhadores em educação (CNTE) e pelo próprio Ministério da Educação (MEC), através de programas profissionais.

A CNTE, criada em 1990, apresenta uma marcante trajetória de lutas em defesa da unificação e fortalecimento dos trabalhadores em educação básica.

A política educacional desenvolvida pela CNTE tem encontrado alguns ecossomado esforços com o ministério da educação, na atual conjetura. Entendendo que "a escola pode e deve ser o mais importante espaço de formação cidadão". O MEC em parceria com o Consed, a Undime e a CNTE, assumiu, em 2004, como uma de suas principais políticas de promoção da qualidade social da educação básica, a valorização dos trabalhadores em educação. ${ }^{6}$

\section{Prática Educativa e Sociedade}

Desde o início da história da humanidade, os indivíduos e grupos travam relações reciprocas diante da necessidade de trabalharem conjuntamente para garantir sua sobrevivência. Essas relações vão passando por transformações, criando novas necessidades, novas formas de organização de trabalho e, especificamente, uma divisão do trabalho conforme sexo, idade, ocupações, de modo a existir uma distribuição das atividades entre os envolvidos no processo de trabalho. Na história da sociedade, nem sempre houve uma distribuição por igual dos produtos do trabalho, tanto materiais quanto espirituais. Com isso vai surgindo as relações sociais, a desigualdades econômicas e de classes. Nas formas primitivas de relações sociais os indivíduos têm igual uso fruto do trabalho comum.

\footnotetext{
${ }^{6}$ Para tanto, implantou, em 2004 a rede nacional de formação continuada, deliberou pela criação do fundo de manutenção e desenvolvimento da educação básica (Fundele) e a pela elaboração dos programas pró-infantil (voltado para a formação inicial em nível médio, de professores que atuam na educação infantil) e o programa nacional de valorização dos trabalhadores em Educação Básica, aqui abordado.
} 
A divisão do trabalho vai fazendo com que os indivíduos passem a ocupar diferentes lugares na atividade produtiva. Na sociedade escravista os meios de trabalho e o próprio trabalhador (escravo) são propriedade dos donos de terras. $\mathrm{Na}$ sociedade feudal, os trabalhadores (servos) são obrigados a trabalhar gratuitamente nas terras do senhor feudal ou a pagar-lhe tributos. Séculos mais tarde, na sociedade capitalista, ocorreu uma divisão entre proprietários privados dos meios de produção (empresas, máquinas, bancos, instrumentos de trabalho, etc.) e os que vendem a sua força de trabalho para obter os meios de sua subsistência, os trabalhadores que vivem do salário.

As relações sociais no capitalismo são, assim, fortemente marcadas pela divisão da sociedade em classes onde capitalistas e trabalhadores ocupam lugares opostos e antagônicos no processo de produção. A classe social proprietária dos meios de produção retira seus lucros da exploração do trabalho da classe trabalhadora. Esta, a qual pertencem cerca de $70 \%$ da população brasileira, é obrigada a trocar a sua capacidade de trabalho por um salário que não cobre as suas necessidades vitais e fica privada, também, da satisfação de suas necessidades espirituais e culturais. A alienação econômica dos meios e produtos do trabalho dos trabalhadores, que ao mesmo tempo a desigualdade social e consequências decisivas nas condições de vida da grande maioria da população trabalhadora.

A desigualdade entre os homens, que na origem é uma desigualdade econômica no seio das relações entre as classes sociais, determina não apenas as condições materiais de vida e de trabalho dos indivíduos, mas também a diferenciação no aceno a cultura espiritual, à educação.

Com efeito a classe social dominante retém os meios de produção material como também os meios de produção cultural e de sua difusão, tendendo a coloca-la a serviço de seus interesses. Assim a educação que os trabalhadores recebem e visam, principalmente preparálos para o trabalho físico, para atitude conformista, devendo contentar-se com uma escolaridade deficiente. Além disso, a minoria dominante dispõe de meios de difundir a sua própria concepção de mundo (ideias, valores, práticas sobre a vida, o trabalho as relações humanas, etc.) para justificar a seu modo, o sistema de relações sociais que caracterizava a sociedade capitalista. Tais ideias, valores e práticas, apresentadas pela minoria dominante como representativos dos interesses de todas as classes sociais, são o que se costuma denominar de ideologia. 
O sistema educativo, incluindo as escolas, as igrejas, as agências de formação profissional, os meios de comunicação de massa, é um meio privilegiado para o repasse da ideologia dominante.

\section{Visão Sobre Educação Segundo Vygotsky, Arendt Hannah e Saviani}

É através da educação que nós fazemos humanos e históricos como autores no modo de refletir sobre a realidade, sobre o mundo e sobre nós mesmos (condição de sujeito) nessa direção a realização do indivíduo como sujeito histórico distingue sua conexão com a coletividade e seu acordo com a mudança social.

Vygotsky assume a tese central de que criando e recriando a cultura em suas relações o humano cria e recria a se próprio. Com essa afirmação concluímos que a subjetividade se traduz quando cada pessoa vai assumindo o papel de sujeito de sua própria história e como ela se articula com a história coletiva e global. A utilização dessa compreensão de sua subjetividade faz que o indivíduo busque sua liberdade na construção da cidadania.

Através da subjetividade, os sujeitos de suas ações se auto produzem em processos coletivos de natureza econômica e cultural na convivência livre com os demais sujeitos sociais. Este sujeito histórico não é algo separado que interage com a realidade, mas é parte integrante desse meio social e histórico que atua. A educação cumpre esse papel ao contemplar os educandos com os instrumentos que lhe são indispensáveis e pertinentes através do ensino/ aprendizagem possibilitando que todos os sujeitos históricos se apropriem desses meios através da preparação para o trabalho, ingresso e participação crítica na vida social e política identificada em seu movimento histórico, articulada as vontades de todos os outros cidadãos reunidos no mesmo espaço e tempo social, o alicerce ético da humanidade se ajusta no reconhecimento de si mesmo como sujeito (individualidade), na liberdade e na autonomia e se constrói quando o ser humano incorpora esses valores.

Para Saviani, a educação (enquanto natureza) parte de um processo de trabalho, ou melhor, constitui-se um. Conforme ele mesmo lembra, o homem é um ser que, constantemente, produz para depois (re) produzir, sendo este produto dado pelo trabalho. E a partir deste movimento histórico que os homens fazem cultura, e a fazem coletivamente. Daí porque se diz 
que ao homem cabe adaptar a natureza, transformá-la, é para dizer que suas necessidades são as suas sabedorias.

De acordo com a visão dos autores supracitados em relação ao homem partindo do ponto histórico que o mesmo é um ser que produz para depois reproduzir sendo este produto dado pelo trabalho mostrado que os homens fazem cultura coletivamente. Assim como Saviani fala dos saberes/ ou produtos subjetivos, hábitos, ideias, os conceitos valores, símbolos e habilidades e os outros tem a mesma visão em relação a educação e o homem é como um sujeito histórico, parte integrante desse meio social que atua na sociedade.

\section{Metodologia}

A metodologia foi através de pesquisas de leituras bibliográficas sobre a visão de alguns autores sobre a educação, sujeito, trabalho e sociedade onde se possa ter uma visão crítica sobre o assunto e que através desse trabalho possa se obter conhecimentos e resultados positivos para todos os desafios tendo uma visão voltada para o desenvolvimento de uma sociedade plena e consciente do seu papel como cidadão e uma educação de qualidade voltada para todas as classes sociais.

\section{Conclusão}

Essa pesquisa teve como principal objetivo reconhecer a importância da história do trabalho e os movimentos sociais das classes trabalhistas e as transformações ocorridas a partir de um processo educativo mais global.

Sabe-se que os membros da sociedade são preparados para a participação da vida social e universal sendo uma atividade humana necessária a existência e funcionamento de todas as sociedades; portanto do conhecimento do cotidiano com base em pequenas observações sobre a educação e o homem como sujeito do processo de estar em constante interação com os outros a fim de compreender a si mesmo e a tudo que está a sua volta, faz parte de um longo processo de interiorização de formas culturais. Ao mesmo tempo em que originam, também modificam 
os comportamentos, as concepções, a forma de tratar as pessoas, de emitir opiniões de perceber, explicar e dar sentido ao mundo em que está inserido.

Pode-se dizer que este Artigo oferece uma panorâmica, abordando vários temas em relação ao assunto supracitado, chamando atenção do leitor para conhecer melhor a história da educação a sua influência para melhoria do trabalho, os movimentos sociais para valorização dos trabalhadores da educação, e as dificuldades das classes sociais que apesar de tantas lutas o capitalismo ainda prevalece nas mãos da minoria e o povo pobre sofrendo as consequências.

A escola assegura aos alunos um sólido domínio de conhecimento de suas capacidades, intelectuais, de pensamento crítico e criativo tais tarefas contribuem para a formação de cidadãos ativos, criativos e críticos, capazes de participarem nas lutas pela transformação social.

Convictos que os objetivos foram alcançados faz-se necessário compreender a importância e a intensidade de refletir, analisar, agir, sentir e valorizar o outro por que a sociedade necessita de pessoas pensantes comprometidas, capazes de produzir conhecimentos de acordo com sua visão de mundo ou com o nível em que está inserido e que o homem se reconhece como sujeito histórico desse processo para transformação da sociedade.

\section{Referências}

ABRUCIO, F. L. Os Avanços e os dilemas do modelo pós-burocrático: a reforma da administração pública à luz da experiência internacional recente. In: BRESSER P.; SPINK, P. (Org.). Reforma do estado e administração pública gerencial. Rio de Janeiro: Editora FGV, 1998, 314pp.

BARNES, R. M. Estudo de movimentos e de tempos: projeto e medida do trabalho. 6 ed. São Paulo: Edgar Blücher, 1977.

CASElla, D. M. A. Administração pública. Webartigos, 2008. Disponível em: <http://www. webartigos.com/artigos/administracao-publica/7063/>. Acesso em: 11 fev. 2017.

CHIAVENATO, I. Introdução à Teoria Geral da Administração. 7 ed. Rio de Janeiro: Elsevier, 2004.

CRUZ, T. Sistemas, Organização \& Métodos. São Paulo: Atlas, 2002. 
DI GIACOMO, W. A. O New Public Management no Canadá e a gestão pública contemporânea. Revista Interfaces Brasil/Canadá, n. 5, 2005.

FIGUEIREDO F. J. S.; OLIVEIRA T. R. C.; SANTOS A. P. M. Estudo de tempos em uma indústria e comércio de calçados e injetados LTDA. - XXXI Encontro Nacional de Engenharia de Produção. Belo Horizonte, MG, Brasil, 2011.

GIL, A. C. Métodos e técnicas de pesquisa social. São Paulo: Atlas, 1991.

HOOD, C. The Art of the state: culture, rhetoric, and public management. New York: Oxford University Press Inc., 1998.

JÚNIOR, C.P. A medicina do Trabalho no Contexto Atual. In: VIEIRA, I.S. Manual de Saúde e Segurança do Trabalho. 3ª ed. Curitiba: Genesis Editora, 1996.

MARCONI, M. A.; LAKATOS, E. M. Metodologia científica. 6. ed. São Paulo: Atlas, 2011.

MATTAR, F. N. Pesquisa de Marketing. $2^{a}$ ed. São Paulo: Atlas, 1999.

OSÓRIO, F. M. Novos rumos da gestão pública brasileira: dificuldades teóricas ou operacionais? Revista Eletrônica sobre a Reforma do Estado, n. 1, 2005.

PAES DE PAULA, A. P. Por uma nova gestão pública. Rio de Janeiro: FGV, 2005.

PEINADO, Jurandir \& GRAEML, A. R. Administração da produção: operações industriais e de serviços. Curitiba: UnicenP, 2007

ROCHA, L. O. Organização e Métodos. São Paulo: Atlas, 1998.

SECCHI, L. Modelos organizacionais e reformas da administração pública. Revista de Administração Pública, v. 43, n. 2, 2009.

TAYLOR, F.W. Princípios de administração científica. 8. ed. São Paulo: Atlas, 1990.

TRIVIÑOS, A. N. S. Introdução à pesquisa em ciências sociais: a pesquisa qualitativa em educação. São Paulo: Atlas, 1987.

YIN, Robert K. Estudo de caso: planejamento e métodos. 2. ed. Porto Alegre, Bookmann, 2001. 
Id on Line Revista Multidisciplinar e de Psicoloqia

Id on Line Multidisciplinary and Psycology Journal

ZOGHBI, J. F. G.; MARTINS, J. E. P. Gestão do conhecimento e da informação em ambientes com elevado turnover na alta chefia: um estudo de caso em projetos de governo. In: CONGRESSO CONSAD DE GESTÃO PÚBLICA, 2 ed., Brasília (DF). Anais. Brasília: Consad, 2009.

\section{Como citar este artigo (Formato ABNT):}

COSTA, Francisca Ilka O.B.; ANDRADE, Iarê L. Prática Docente, Educação e Sociedade. Id on Line Revista Multidisciplinar e de Psicologia, Julho de 2017, vol.11, n.36, p.93-103. ISSN: 1981-1179.

Recebido: 19.10 .2016

Aceito: 17.06.2017 